\title{
Estimating Ethnic Identities’ Importance among Iranian Tribes
}

\author{
Maryam Cheheltani ${ }^{1}$, Nurdeng Deuraseh ${ }^{1}$, Zaid Ahmad $^{1} \&$ MS Sabran $^{1}$ \\ ${ }^{1}$ Department of Government \& Civilization Studies, Faculty of Human Ecology, UPM, Malaysia \\ Correspondence: Maryam Cheheltani, Department of Government \& Civilization Studies, Faculty of Human \\ Ecology, UPM, Malaysia. Tel: 60-17-622-5254. E-mail: maryamcheheltani@yahoo.com
}

Received: May 5, 2012 Accepted: June 2, 2012 Online Published: August 17, 2012

doi:10.5539/ass.v8n11p58 URL: http://dx.doi.org/10.5539/ass.v8n11p58

\begin{abstract}
Unappreciation and inattention to ethnic identity weakens unity, and this is a threat for national integrity and solidarity in culturally diverse societies. For this reason, governments and authorities try to strengthen national integrity through utilizing local values. This study rates local values' Importance among the minorities that settled in Tehran through a questionnaire. The city of Tehran as the capital and largest city in Iran is one of the main immigrant receiving areas in the world with $31 \%$ reception of immigrants. This research validated the results of the questionnaire through in-depth interview with Iranian cultural experts. Evidently, paying attention to ethnic identity establishes a tradition which will continue in history for the later generations. Moreover, attention to ethnic identity can stimulate people's patriotism. This paper suggests that majority of Iranian groups show interest in local values' Importance. The interest of different tribes in their own ethnic identity can has tremendously important roles in implementing or not implementing major plans and long-term cultural programs.
\end{abstract}

Keywords: local values, local values' importance, Iranian tribes

\section{Introduction}

Iran has a population of over seventy million (Rastegar, 2009). Because of Iran's unique location in the world, it has been constantly under the influence of immigration by different races and tribes (Golami, 1996). There are a number of other national and ethnic groups living in various parts of Iran such as Azarbaijanis, Kurs, Lurs, Arabs and Baluches. They have different histories, languages, housing, culture and tradition. Tehran is the capital of Iran and the official religion is Islam. The Iranian government system is Islamic republic. The Persians are the largest ethnic group in Iran and they speak the Persian language (Beehner, 2006).

According to the Iranian constitution, a national census is conducted every 10 years. Based on the latest census in 2006, the population of Iranian ethnic groups are as follow: Persians, 65\%; Turks, 18\%; Kurds, 7\%; Lurs, 6\%; Arabs 2\%; and Baluch people 2\% (Hafeznia, 2002). After Persians, who settled all over the country, another large group in Iran is the Azerbaijanis. Today, they speak Turkish and live in Azerbaijan, in the northwest of Iran. They can also be found in the Ardebil provinces, Tabriz, Urumiyeh, Zanjan, Qazvin, Hamedan, Tehran, around Qom and Saveh, Khorasan, and many other parts of Iran (Shaffer, 2006). There are two theories about the origin of Iranian Azerbaijanis. The first is that they migrated to Iran in the 7th and 11th centuries or invaded Iran at various times. The second is that they were with the Medes when they came to Iran and confederated with native tribes to establish a Medes dynasty (Society).The Medes are divided into two major groups: the small Medes whom are called today as Azerbaijan or habitat Turks and the big Medes which include Hamadan, Tehran, Esfahan and Kermanshah (Nasirpoor, 2008).

The other main tribes in Iran are the Kurds, Arabs, Baluches, and Lurs (Bradley, 2006). The Kurds people reside mainly in Kurdestan located in the northwest of Iran. The Kurds people have an ancient history. Iranian researchers believe that the Kurdish people are the survivors of one of the Medes groups. They live in Iran in Kurdestan, Kermanshahan, south of the Western Azerbaijan, north Khorasan, Gilan, and Luristan. They speak Kurdish, an Indo-European language of the Iranian branch (Ebrahimi, 2008).

Along the Iranian-Iraqi border in southwest Iran is a population of Arabs. They speak Arabic language. On the basis of historical evidence, the first Arabian tribes migrated to Khuzestan, southwest of Iran in the early centuries AD. Some of the Arabian tribes live in the Khorramshahr, Ahwaz and Dezful (Hussein, 2008) Most of 
the Baluches tribes in Iran reside in Baluchistan, a part of the Sistan and Baluchestan province in southeastern Iran. Baluchestan is a big state that has two main parts. The big part is in Iran and the populated part is in Pakistan. The Baluch people are mostly Sunni Muslims and speak Baluchi (Askari, 1991). The Lurs are a branch of Iranian people. They live mostly in South-western Iran. Lur people speak Luri. Historically, the Lurs migrated to Iran from Central Asia, Eastern Europe, Northern India, Eastern Iran or Afghanistan (Peyman, 2007). The Lur people are divided into two major groups: the Lor-e-Bozorg, residing today in Khuzestan, Chaharmahal and Bakhtiari, parts of Lorestan, and parts of Isfahan and the Lur-e-Koochik, which can be found in Lurestan (Peyman, 2007).

Ethnic identity includes some part of thought, understanding, feelings and behaviour proper for the members of the ethnic group (Carmen, 1998) Ethnic identity refers to certain characteristics and attributes which distinguish an ethnic group from others, unifies the members and creates affection among them (Ahmadloo, 2002). Such ethnic symbols as the honouring and loyalty to religion, language, traditions and cultural prides are called ethnic identity. In such an identity, there is much more unity among the members and society (Rezai, 2007). Altai (2003) believes that ethnic identity is a given collection of cultural, social and religious factors which emerge in a human group and separate it from others. The growth of an ethnic identity is a basic need for everyone through which one can create a mutual historical feeling and a feeling of belonging in him/herself (Altai, 2003). Ethnic identity, such issues as ethnic customs and traditions, ethnic clothes, traditional local music, ethnic ceremonies and dances, ethnic language and tribal values have been focused (yusofi, 2001). National identity is a feeling of affection and commitment to society which brings about social unity and forms some parts of personal identity (Ebrahimi, 2008). National identity distinguishes a nation from other nations and makes it known to others. It is considered as the main framework of the political geography of every country. The most important ingredients of national identity are country, religion, language, literature, government, rituals and traditions. Loyalty and affection to each of the aforementioned elements in a society determines national identity (Hafeznia, 2002).

Since the subject of the study is about local values' importance among Iranian tribes, the statistical population and sample population of this study are taken from one of the major cities of Iran which is Tehran. It hosts a large number of ethnic immigrants. Therefore, Tehran, the capital city of Iran has been selected. It has the highest level of ethnic diversity among other Iranian cities (Masjedjamei, 2010)

Iran is a country of ethnic diversity, which, despite of all cultural similarities, put emphasis on their ethnic identities. Ignoring these identities and values, creates ethnic oriented provocations to defend from local identity and tradition. This problem can be a real threat to Iranian national solidarity. Alienation from other Iranian ethnic and cultural transactions based on distrust will be the reason of enmity, violence and sometimes subservient activities. This paper tries to assess the degree of importance of identities to Iranian ethnic groups. We believe that consolidating unity, solidarity and national understanding is of utmost importance in a country where various ethnic and cultural groups live together. Attention to these important issues can guarantee political stability, national solidarity and social security.

\section{Background of Problem}

Iran has been constantly under the influence of immigration by different races and tribes (Khanmohammadi, 2009) or at least as a crossing point, Iran has witnessed people and ethnic groups crossing the country from eastern lands to the western lands leaving behind their cultural ethnic social and lingual customs and traditions (SalehiAmiri, 2009). These things however have changed the Iranian society from a homogeneous unit into a heterogeneous unit from integration of different tribes and ethnic groups including Azaris, Kurds, Baluches, Lurs, Turks and Arabs. The simple racial uniformity has been replaced with intermingling of different groups which has made Iran a multicultural country (Hajiyani, 2006).

Paying attention to ethnic identity establishes a tradition which will continue in history for the later generations. Moreover, encountering each of ethnic identity can stimulate people's patriotism (Morshedizadeh, 2003). Lack of attention to ethnic identity and identities is a real threat to different tribes. Iran's history confirms that Iranians from any tribe or ethnicity have concerns on integrity and their unity had been based on racial and historical continuity. This alliance is the secret of Iranian survival and has saved the country from foreign occupation (SalehiAmiri, 2009). Ethnic identities bring about unity among the people of that tribe or nation and the strength unanimous among them. Ethnic identity transfer from generation to generation. Although, some of them remain intact, some undergo slight changes and some are forgotten (Weber, 1993). On the other hand, ethnic identity can play very important roles in implementing or not implementing major plans and long-term cultural programs. The more interest people have in local values, the better and more cooperative they are in national projects.

In internet or in Iranian universities' libraries, there are plenty of researches regarding ethnic identity. These 
researches are belonging to urban residence, rural people or nomads, too. These papers always discuses about ethnic basis and psychological analysis of related people. Lack of information about urban immigrants is the main reason of lack of research at this area. This paper is using current data and interpretation current circumstances of different ethnics' immigrants to Tehran.

\section{Research Methodology}

Since the subject of the study is about cultural diversity and cultural interaction among Iranian ethnic groups, the statistical population and sample population of this study is taken from Tehran, one of the major cities of Iran which has hosted a large number of ethnic immigrants. Tehran has been selected because it has the highest level of ethnic diversity among other Iranian cities. In this study, the researcher was faced with a 10 million population as case study. The minimum sample size according Cochran formula is 384 people. The data for the study was collected through simple random data collection.

After collecting the questionnaires and conducting a demographic analysis of them, it was found that $48 \%$ of the respondents were male, and $52 \%$ were female. Thirty-five percent of the respondents stated Tehran as their birthplace (Fig.1.).

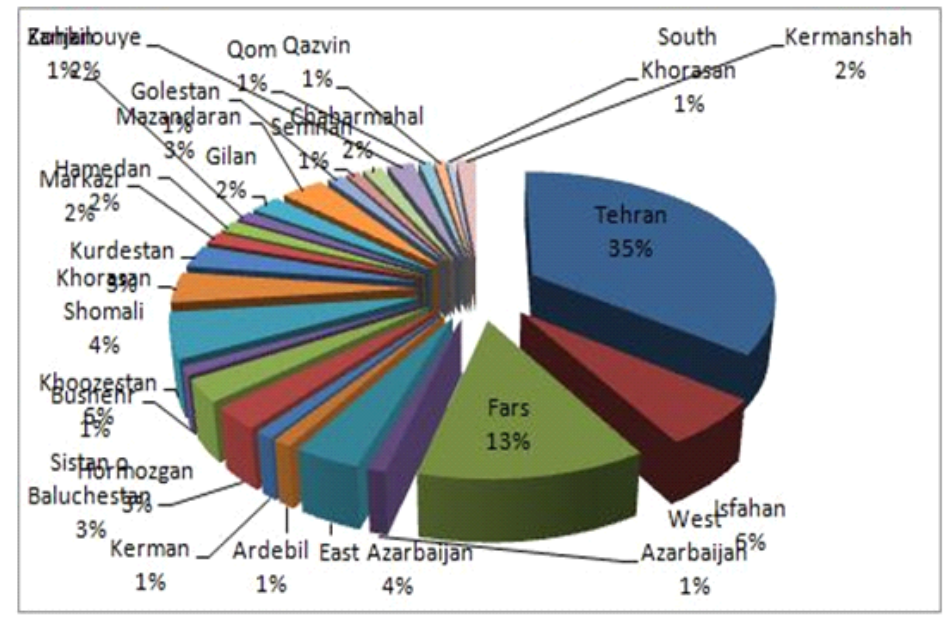

Figure 1. Participants according birth place's stats

These respondents also include those whose parents have immigrated to Tehran and as a result they are regarded as natives of Tehran. After Tehran, the highest number of respondents belongs to Fars province (with Shiraz as the centre). Isfahan and Khuzestan also have the highest number of participants in the study (Fig.1). Majority of the participants in this research speaks Farsi (Fig. 2). It includes second generation of other ethnic groups who speak Farsi after years of staying in Tehran.

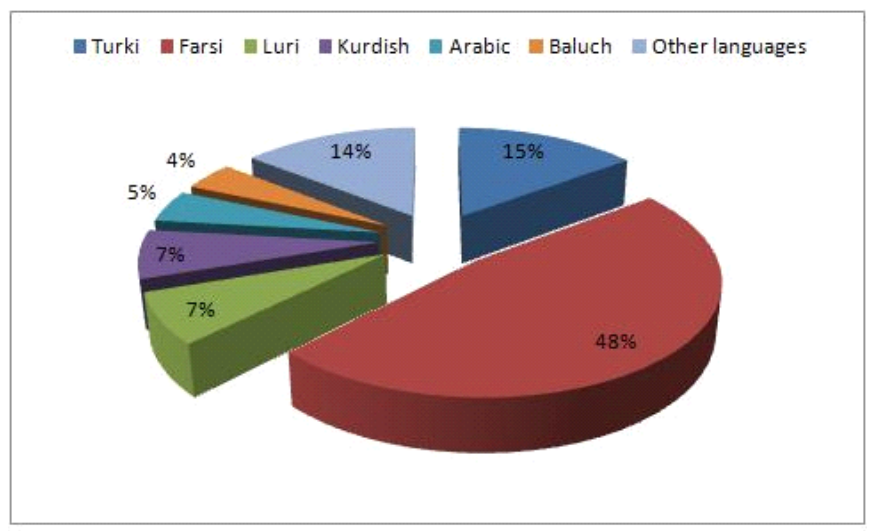

Figure 2. Language of participants

Majority of the respondents belong to Fars ethnic group, followed by Turks (Fig. 3). Twenty-five percent of respondents are Fars, $21 \%$ are Turks and other various small groups such as Armenian, Asurian, Jews, Tajik and Afghan comprised $26 \%$ of the participants. 


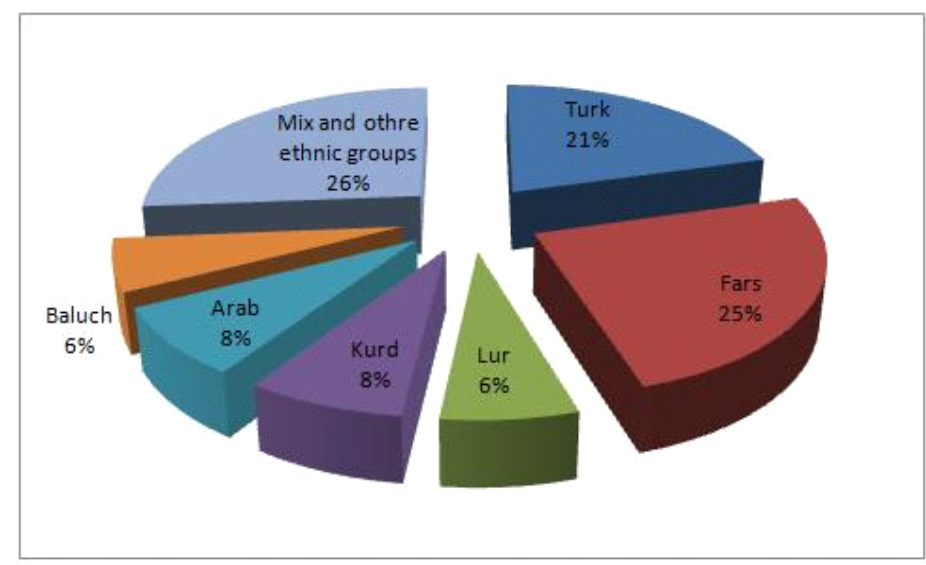

Figure 3. Respondents' ethnic group

Majority of the respondents belongs to $25-34$ years age group which is 150 persons out of 384 (Fig.4). The age groups of other participant are as follows:

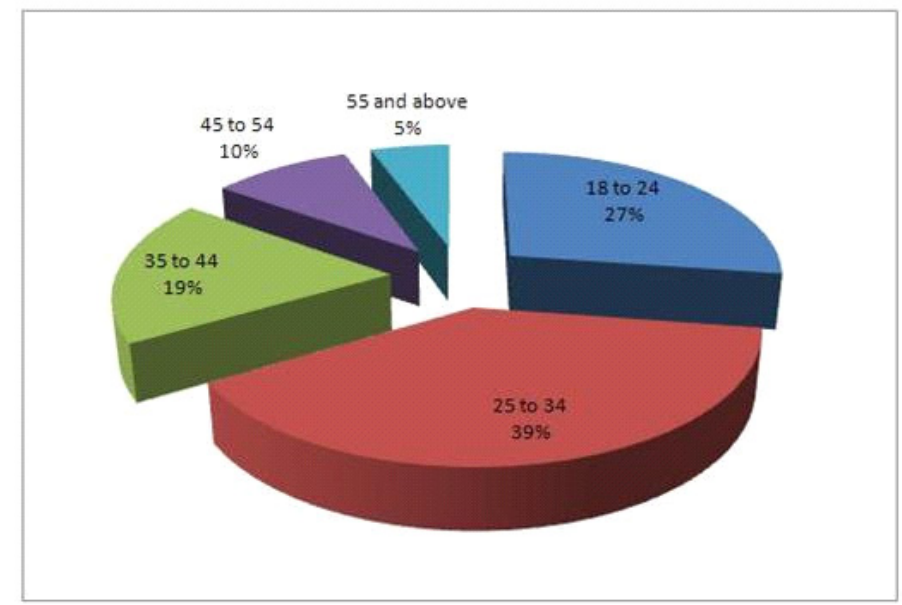

Figure 4. The age of respondents

For the education of the respondents, it was found that $35 \%$ have B.A. or B.S, $25 \%$ have post-diploma, $20 \%$ have diploma $18 \%$ have M.A. or M.S. and higher degrees and the remaining $2 \%$ are illiterate.

Table 1. Respondents' education level

\begin{tabular}{lll}
\hline 1 & Illiterate & $2 \%$ \\
\hline 2 & Diploma & $20 \%$ \\
3 & Post Diploma & $25 \%$ \\
4 & Bachelor & $35 \%$ \\
5 & Master\& above & $18 \%$ \\
\hline
\end{tabular}

The information above confirms that the respondents belong to different ethnic, cultural and language groups which can be accepted as a normal sample of the whole country. Also, majority of respondents are young educated people.

\section{Discussion and Analysis}

\subsection{Customs and Traditions}

One of the most important aspects of each tribe's ethnic identity is its customs and traditions. Popular customs include such things as the lifestyle, habits and special traditions of a nation, community or group of people. Moreover, they are sets of manners which have become a habit and the people belonging to a class do them. The 
popular customs of tribe or nation bring about unity among the people of that tribe or nation and the strength unanimous to them. The popular customs and traditions of a tribe are passed down from one generation to another. Although, some of them remain intact, some undergo slight changes and some are forgotten (Weber, 1993) evidently, we can try to strengthen the national integrity through utilizing symbols of rituals. Paying attention to local customs establishes a tradition which will continue in history for the later generations. Moreover, encountering each of these symbols and rituals can stimulate people's patriotism. These symbols and rituals, as ingredients of the national integrity, are hence necessary. Referring to this, the statement in the questionnaire is "I respect my local custom and I usually try to practice it ". More than $59 \%$ of the respondents agree to this statement and 16 percent disagree while $25 \%$ of respondents are uncertain.

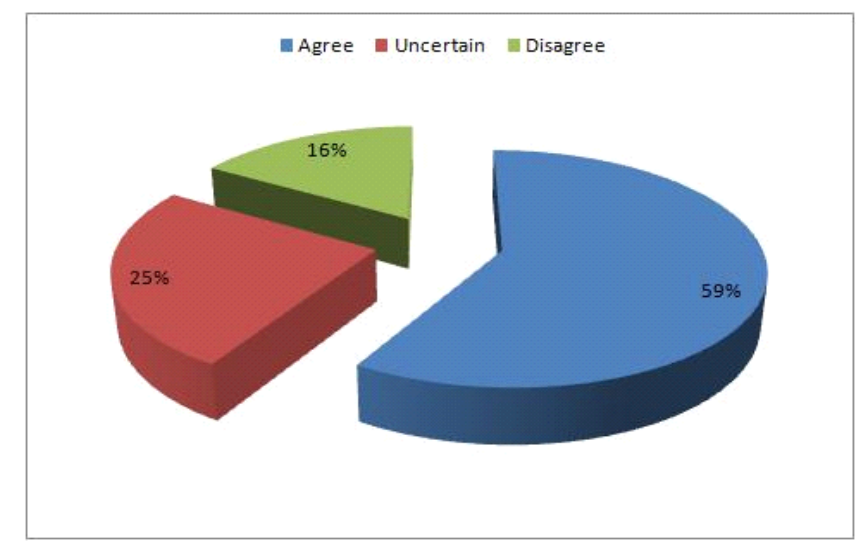

Figure 5. I respect my local custom and usually try to practice it

This shows that majority of the respondents maintains high regard in practicing local customs and traditions.

\subsection{Interest in Local Costumes}

Local clothes are other symbols of ethnic identity and its importance and usage by Iranian ethnic groups have been included in the questionnaire. Local clothes represent the culture of a tribe and are the special symbols of that tribe as well. Depending on its geographical location and economic and cultural state, each Iranian tribe has its own clothes. The diversity in local clothes is wide.

For the item, "I respect my local costumes and usually try to use it", 112 people which is $29 \%$ of respondents agree with this statement and $39 \%$ disagree while $32 \%$ are uncertain (Fig. 6.). Most of the respondents respect local costumes and they wear it in their hometown but are not able to use it at this new urban lifestyle because in Tehran wearing traditional costumes is not normal.

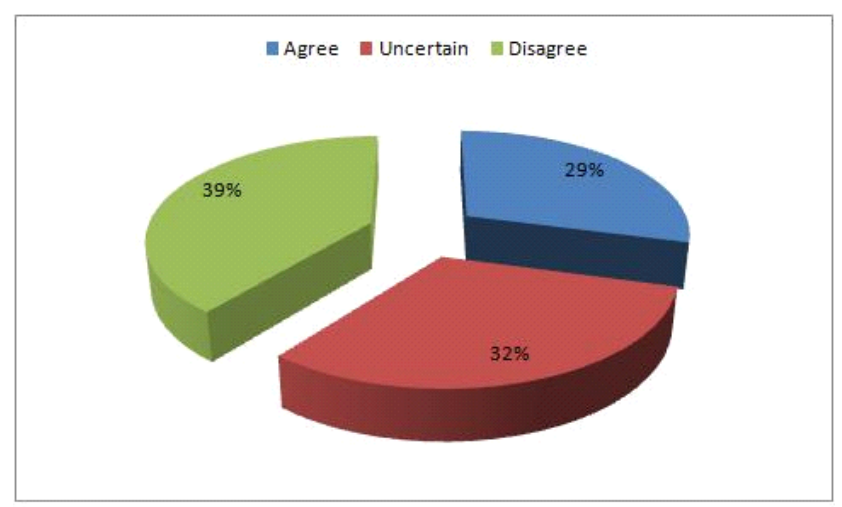

Figure 6. I respect my local costumes and usually try to use it

The results obtained in the section indicate that those who are against using local clothes are more than those who are for using such clothes. This means that majority of the people, especially the youth, are not interested to wear local clothes regularly. Many of these people are not happy to be noticed by passers-by because of wearing local clothes. According to an unwritten law and because of Tehrani citizens' reputation during the past 100 years (which originates from cultural problems and improper composition of national TV programs), presently some of the youths prefer to change their native accents and speak in Tehrani accent in public places. So they are not 
inclined to use their local clothes.

\subsection{Interest in Traditional Music}

Traditional music is another important and valuable symbol among Iranian ethnic groups. Every Iranian tribe has a kind of music corresponding to their tribal characteristics and cultural manners.

For this subject, the statement is "Local music is an inseparable part of my life" and 257 respondents or $67 \%$ agree with the statement, $15 \%$ disagree and $18 \%$ are not sure (Fig. 7 ).

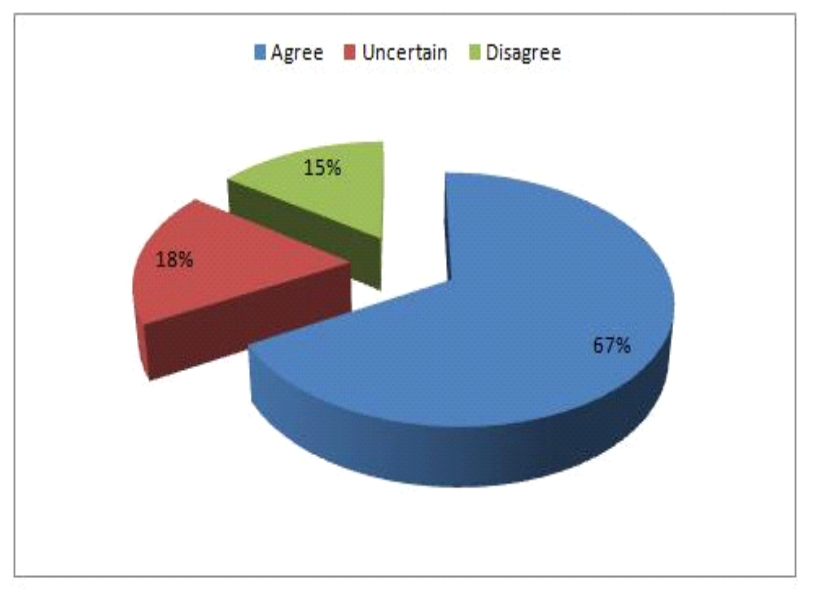

Figure 7. Local music is an inseparable part of my life

The results of this section indicate that Iranian ethnic groups are very interested in their native folk music. These people regard music as a part of their lives and listening to such music is a part of their everyday routine. The major reason for interest in folk music is that such music has a direct relation with ethnic life style, religious beliefs, and their natural environment. For such people, folk music reminds them of their past.

\subsection{Interest in the Local Dances}

Local dances also have a good status among Iranian ethnic groups as a symbol of tribal identity. The major categories of dances in Iran are traditional, historical, religious, ceremonial and local-tribal dances. The ceremonial dances include epic dancing; religious dances include Dervish dancing; local and tribal dances include Turkish Kurdish Azeri, etc. Dances from different areas of Iran have different themes such as ritual and religious themes, epic themes, dramatic themes, and mourning and remedial themes (Mahfoz, 2009).

Regarding this, the statement in the questionnaire is"Local dance is the most important part of my entertainment". For this 219 persons or $57 \%$ agree with the statement, $8 \%$ disagree and $35 \%$ are not sure (Fig.8).

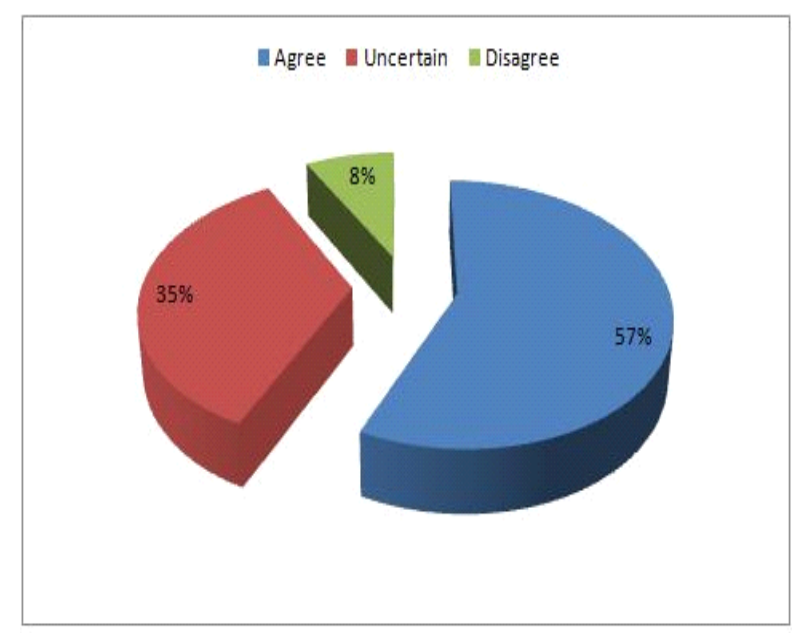

Figure 8. Local dance is the most important part of my entertainment

The results show that Iranian ethnic groups are very interested in folk dances and they believe in using such dances in different ceremonies. The reason for the respondents' agreement with folk dances is that dance is 
historically a reflection of traits and spirit of different ethnic groups in encountering the world. The art of dancing in Iran is so rooted in the mind and life of the dwellers of this country that it is included in many legends and myths common among ethnic people.

\subsection{Interest in the Local Language}

Language is a proof of ethnic identity and the written symbol and history. To assess interest in local language, the statement"I always speak in my hometown language when I am at home" is used. 231 respondents or $60 \%$ agree meaning they speak their hometown language when they are at home. 94 or $25 \%$ of respondents disagree which means they don't practice their hometown language when they are at home and 59 or $15 \%$ are uncertain. It may be that the $25 \%$ who disagreed cannot speak their language or they don't have anybody to practice their language with.

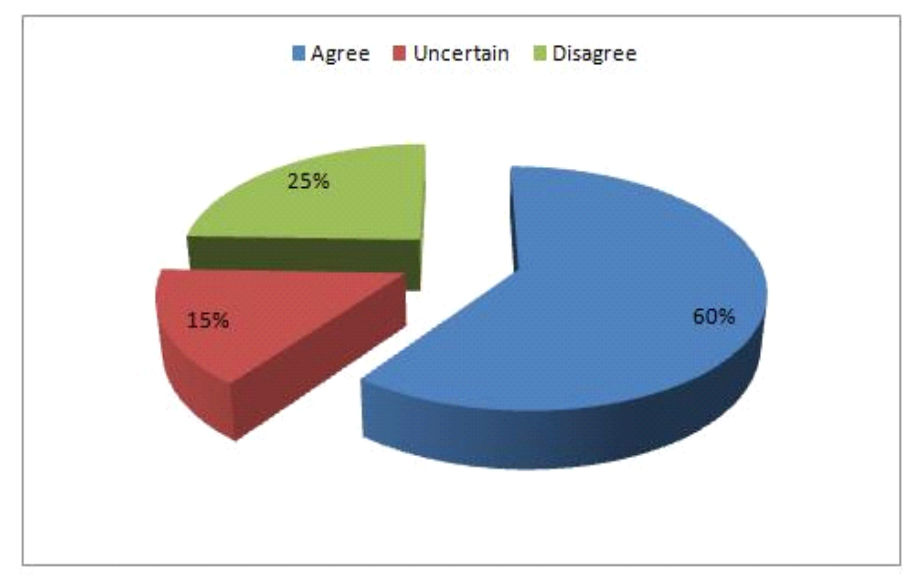

Figure 9. I always speak in my hometown language when I am at home

According to the results of the study, Iranian ethnic groups are very interested in everyday use of their language. They said that they use their local language at home every day. The reason for respondents' agreement in using their ethnic language is because of the fact that utilizing ethnic and local languages and accents is one of the most common demands of the minorities. There are, however, people who have declared that they do not use their local language and have no interest in it at all. The reason for this is intentional or unintentional neglect of ethnic languages and accents is due to the influence of media and others.

\subsection{Ethnic Groups' Travels to Their Hometowns}

Another issue raised in the questionnaires is about ethnic groups' travels to their hometowns. The statement"Traveling to my home town is part of my annual plan" is used. Every year a lot of people from different provinces who belong to different tribes immigrate to larger provinces like Tehran, the capital city of Iran.

Recently, the population of Tehran has had a $3 \%$ growth, $1 \%$ of which is the due to immigration. In some cities located in the west of this province, the population has even had an $8 \%$ growth. Such a rapid and unplanned growth in a major city like Tehran has brought many problems for urban management. The reason for their immigration to Tehran and other major cities of Iran is to get away from poverty, shortage of food, war, unemployment, and lack of security, natural disasters and or to have access to education, better housing, better income or more healthcare services (Tamizifar, 2005).

According to the results, $77 \%$ of the respondents have declared that traveling to their hometowns is a part of their schedule every year (Fig.10). The results show that Iranian ethnic groups have a particular interest in returning to their hometowns but they have resorted to immigration due to certain circumstances. But if the conditions are suitable, they would return to their hometowns. It has been mentioned that some groups of respondents have disagreed having stated that they have no interest in returning to their hometowns. The possible reason for such disagreement is that they have no interest in their native identity. Some of these respondents stated their origin as Tehrani, although they are for example Turk or Kurd. 


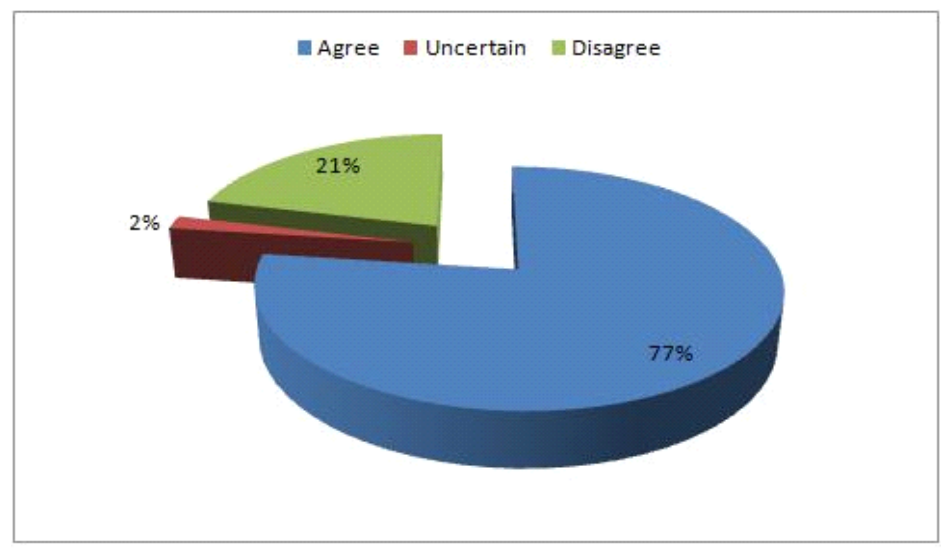

Figure 10. Traveling to my home town is part of my annual plan

According this statement $77 \%$ of the respondents or 296 people have annual plan to visit and spend their time in their home town. It means that although many people have left their area many years ago, they have an emotional attachment to their hometown and have to visit at least once a year. Two percent are uncertain and $21 \%$ of respondents don't have any special plan for a trip to their hometown.

\section{Conclusion and Contribution}

The survey is conducted among 384 people from different ethnic groups and tribes in Iran, including women and men, young and old, educated and non educated people. Demographic analysis categorizes the participants' origin to 26 different areas, exactly according Iran's 26 states. The biggest numbers of participants are from Tehran with 133 participants. This is expected because Tehran has more than 10 million population from different ethnic groups and tribes from different areas of the country. This is due to high immigration rate since 30 years ago as shown in Table 2. The most powerful statement amongst our 6 main local estimator questions is "Traveling to my hometown is part of my annual plan". It shows that people who are originally non Tehranian, try to maintain their connection to their motherland by have at least one trip a year. Another powerful cultural value amongst immigrants to Tehran found in this study is local music. On the other hand, the weakest is local costumes. It means that Iranian immigrants are not keen to wear their traditional dress in their new home. For this reason despite of many ethnic groups living in Tehran, it is very difficult to see a person with local or traditional dress. Table 2 is the summary of respondents' answers.

Table 2. The important cultural values of Iranian people

\begin{tabular}{llrrr}
\hline No & Statement (local value) & Agree & Disagree & Uncertain \\
\hline 1 & I respect my local customs and I usually try to practice it. & $59 \%$ & $16 \%$ & $25 \%$ \\
2 & I respect my local costumes and I usually try to use it. & $29 \%$ & $39 \%$ & $32 \%$ \\
3 & Local music is an inseparable part of my life. & $67 \%$ & $15 \%$ & $18 \%$ \\
4 & Local dance is the most important part of my entertainment. & $57 \%$ & $8 \%$ & $35 \%$ \\
5 & I always speak in my hometown language when I am at home. & $60 \%$ & $25 \%$ & $15 \%$ \\
6 & Traveling to my hometown is part of my annual plan. & $77 \%$ & $21 \%$ & $2 \%$ \\
\hline
\end{tabular}

This research only surveyed 6 main cultural elements of ethnic groups and tribes in Iran. It is recommended to survey all cultural as well as sub cultural elements. In addition, a comparison between local and national values can give a clear picture of the trend of immigrants' values after one or two generations living outside of their motherland.

\section{References}

Adamzadeh, F. (2003). The Effects of Globalization on EducationProceedings of the first conference on globalization and education. Educational Innovations Quarterly, 22.

Ahmadloo, H. (2002). The relationship between national identity and ethnic identity among Tabrizi youths. National studies quarterly, 69(13), 123.

Ali. (2002). People. farhang, 3(2), 12. 
Altai, A. (2003). Ethnic Identity Crisis in Iran. Tehran: Shadgan.

Askari, N. (1991). An introduction to Baluchistan. Tehran: Donyaye Danesh.

Beehner, L. (2006). Iran's Ethnic Groups. Tehran: Foreign Affairs (Council on Foreign Relations).

Bradley, J. (2006). Iran's Ethnic Tinderbox. The Washington Quarterly, 30(1), 75.

Carmen, G. (1998). Ethnic identity and Adolescence. California: Sandiego University.

Davoodi, N. (2007). Language, Language Planning, and National Solidarity: A Look at Iran. Proceedings of the national conference on Policies and Strategies. Tehran: The Center for Strategic Researches.

Ebrahimi, G. (2008). A sociological study of identity types among the youth. Nationally studies quarterly, 8(33), 140.

Ghasem Mohadesi, \& Javad Ghalibaf. (1998). An Encyclopedia of Children and Adolescents (Vol. 2). Tehran: Peyame Azadi.

Golami, Y. (1996). Art in Iran. Magazine keyhane farhangi, 11(29), 72.

Hafeznia, M. R. (2002). Political geography of Iran. Tehran: Samt.

Hajiyani, E. (2006). Patterns of ethnic politics in Iran. Journal of Strategic Studies, 7(2), 12.

Hussein, H. (2008). Ethnic and Religious Minorities in Iran. Washington: Congressional Research Service.

Khanmohammadi, K. (2009). Cultural Elements for Resistance by Iranians. National studies quarterly, 18(2), 23.

Mahfoz, F. (2009). Dance history of Iran. Journal of people culture, 9(29), 26.

Mahshun, H. (1994). The History of Iranian Music. Tehran: Simorgh.

Masjedjamei, A. (2010). The study on the research plan for the amount of goods and cultural services consumption. Tehran: Farhang.

Morshedizadeh, A. (2003). Symbols and rituals in Iran after the revolution and their role in the National Solidarity . Journal of Strategic Studies, 9(4), 76.

Nasirpoor, E. (2008). Turks tribes in Iran. Culture and civilization, 23(Social Sciences), 5-9.

People of Iran: Iranian Ethnic Groups. In Iran Chamber Society. Retrieved Apri 14, 2012, from http://www.iranchamber.com/people/articles/iranian_ethnic_groups.php

Peyman, M. (2007). Lurs, Iranian tribes. Culture and civilization, 12(Social Sciences), 3-7.

Rastegar, H. (2009). Tourism Development and Residents' Attitude: A Case Study of Yazd. Journal of Tourism, $4(2), 203-211$.

Rezai, A. (2007). Tendency to national and ethnic identity in Iranian ethnic groups. National Studies Quarterly, 9(4), 18.

Rudolf, S. (1997). Ethnic Conflicts and their Effects on the International Community. The journal of defensive politics, 10.

Sahabi, H. (1994). Costumes and traditions of Iranian tribes. Tehran: Khojasteh.

Sahm, A. (1994). Political Culture and National Symbols: Their Impact on the Belarusian Nation - Building Process. Nationalities Paper, 64.

SalehiAmiri, R. (2009). Management of Tribal Conflicts. Tehran: The center for Strategic Researches.

Sani, M. (2005). An introduction to Iranian culture and identity. Tehran: Tamadone Irani.

Shaffer, B. (2006). Iran's Volatitle Ethnic Mix. New York: International Herald Tribune.

Siiufolahi, S. (2011). Human Rights according to Independence and National Soverenity. Vatan, 38.

Tamizifar, R. (2005). Reasons Migration of Ethnic. Tehran: Tehran University.

Weber, M. (1993). Basic concepts in sociology. Tehran: Markaz Publication.

Yunosi, A. (2008). The National Unity and Solidarity of Iranians: Fundamentals and Origins. Tehran: Shadan.

Yusofi, A. (2001). Tribal Relationships and their Effects on the National Identity of Tribes in Iran. The National Studies Quarterly, 9(4), 17.

Zolfaghari, H. (2007). Religious and Iranian identity in Persian proverbs. Nationally studies quarterly, 22. 